\title{
ANTI-AMERICANISMO, PRO-AMERICANISMO Y SENTIDO COMÚN EN AMÉRICA LATINA ${ }^{1}$
}

\author{
Arlene B. Tickner \\ Carolina Cepeda M. \\ José Luis Bernal
}

Hablar de América Latina como anti o pro-americana supone que sus sentimientos hacia Estados Unidos determinan una parte de su identidad. ${ }^{2}$ Según Alan McPherson, la región es un caso singular por un anti-americanismo arraigado que ha moldeado, en cierta medida, la identidad del continente entero. ${ }^{3}$ Por ejemplo, países como Ecuador, Venezuela, México y Cuba se identifican como focos de sentimiento anti-estadounidense por los discursos y políticas que sus gobernantes han expresado hacia Washington en distintos momentos históricos. $\mathrm{Al}$ contrario, otros como Colombia y Perú se catalogan como nichos de pro-americanismo por la cercanía estrecha que sus gobiernos han tenido con el de Estados Unidos.

Pese a lo anterior, la mayoría de los análisis sobre sentimientos pro y anti-Estados Unidos se enfocan en las actitudes de quienes toman las decisiones y de las élites políticas y económicas, con escaso o nulo interés por las percepciones de la población en general.

${ }^{1}$ Los autores desean agradecer a Ralf J. Leiteritz por la invitación a retomar la idea de constructivismo de sentido común.

${ }^{2}$ Peter J. Katzenstein y Robert O. Keohane, "Varieties of Anti-Americanism: A Framework for Analysis", en Peter J. Katzenstein y Robert O. Keohane (eds.), AntiAmericanisms in World Politics, Ithaca, Cornell University Press, 2007, pp. 12-15.

3 Alan McPherson, "Anti-Americanism in Latin America", en Brendon O'Connor (ed.), Anti-americanism: History, Causes, Themes, vol. 3: Comparative Perspectives, Oxford, Greenwood World Publishing, 2007, p. 77. 
Así, cuando se alude a las relaciones de "amor" y "odio", se hace referencia a los discursos públicos de Álvaro Uribe, Hugo Chávez o Evo Morales, los textos escritos de José Martí o José Enrique Rodó, o las hazañas políticas de Fidel Castro o Augusto Sandino, con lo que la identidad de los Estados termina personalizándose y, por extensión, simplificándose.

Si bien el estudio del pro y anti-americanismo aporta elementos interesantes sobre cómo piensan determinados sectores sociales, pierde de vista una dimensión fundamental de las percepciones -el sentido común de las masas-, omisión que es reforzada por la teoría de las relaciones internacionales y la política exterior a la hora de abordar el problema de la identidad estatal. Teorías como el neorrealismo y el neoliberalismo suponen que los Estados son actores unitarios a cuyo interior no es necesario mirar; el realismo clásico, el liberalismo y los modelos de toma de decisiones, por su parte, sugieren que los únicos actores que importan a la hora de entender la identidad nacional son los estadistas, las élites y quienes toman las decisiones; y el constructivismo, pese a rescatar el carácter social e intersubjetivo de la identidad de los Estados, centra su atención en éstos como si fueran entes reificados.

Con el fin de incorporar la población nacional al análisis de la identidad en política internacional, Ted Hopf ${ }^{4}$ plantea la idea de common-sense constructivism o constructivismo de sentido común. $\mathrm{Su}$ objetivo es incluir a las masas en el estudio de las relaciones internacionales, mostrando que las identidades de los Estados no son resultado exclusivo de lo que piensan las élites, sino de un proceso en el que intervienen otros sectores sociales. Haciendo uso de los planteamientos de Hopf, el objetivo de este artículo es desafiar en dos dimensiones los análisis tradicionales que atribuyen identidades anti o pro-americanas a los Estados latinoamericanos. Primero, al no tomar en cuenta las percepciones y el sentido común de las masas, argumentamos que éstos resultan incompletos. Segundo, mediante el examen de dicho common-sense, reflejado en los resultados de las encuestas de Las Américas y el Mundo,

${ }^{4}$ Véase Ted Hopf, "Common-sense Constructivism and Hegemony in World Politics”, International Organization, vol. 67, núm. 2, 2013, pp. 317-354. 
constatamos la existencia de posiciones identitarias complejas y múltiples que retan la idea de una identidad homogénea.

Para esto, el artículo inicia con una discusión de la literatura sobre anti y pro-americanismo en América Latina con el fin de identificar sus tendencias principales y limitaciones a la hora de entender los orígenes y la construcción de la identidad estatal. En la segunda sección utilizamos los datos de Las Américas y el Mundo para construir el marco de percepciones que tienen los ciudadanos de Brasil, Colombia, Chile, Ecuador, México y Perú ${ }^{5}$ respecto a Estados Unidos, lo que ofrece una aproximación preliminar al sentido común de estas masas. Finalmente, el artículo concluye que al tomar en cuenta las percepciones que tiene la opinión pública latinoamericana sobre Estados Unidos es posible comenzar a matizar las atribuciones tajantes de anti o pro-americanismo que se han hecho a la región.

\section{IDENTIDAD EN AMÉRICA LATINA: ANTI-AMERICANISMO Y PRO-AMERICANISMO}

Según algunos autores, América Latina se destaca entre distintas regiones del mundo debido a la existencia de identidades anti o pro-americanas muy marcadas. ${ }^{6}$ Pese a ello, y como mostraremos más adelante, es común encontrar manifestaciones simultáneas de afecto y desafecto en muchos países. Por un lado, es habitual el rechazo por lo que Washington hace en el sistema internacional,

${ }^{5}$ Abordar la opinión pública de sólo seis países dificulta ofrecer reflexiones y conclusiones generales sobre toda América Latina. Como se verá más adelante, este trabajo tiene la intención de alejarse de los enfoques universalizantes y reconocer las particularidades y especificidades del sentido de común de cada país. No obstante, en la sección de análisis de datos se hace referencia a "América Latina" o "Latinoamérica" para agrupar los casos de Brasil, Colombia, Chile, Ecuador, México y Perú, con el fin de agilizar la redacción antes que ofrecer una generalización sobre todos los Estados que componen la región.

${ }^{6}$ Véase McPherson, "Anti-Americanism in Latin America”, pp. 77-80; Andy Baker y David Cupery, "Anti-Americanism in Latin America. Economic Exchange, Foreign Policy Legacies, and Mass Attitudes toward the Colossus of the North", Latin American Research Review, vol. 48, núm. 2, 2013, pp. 106-130. 
dado su historial de intervenciones en la región y sus aspiraciones de hegemonía. ${ }^{7}$ Por el otro, las opiniones son más positivas cuando se habla de lo que Estados Unidos $e s^{8}$ y aparecen sentimientos como la admiración, asociada a ideas como la prosperidad y el éxito de la sociedad estadounidense. No obstante, la mayoría de la literatura sobre actitudes frente a Estados Unidos se puede dividir entre la que analiza el anti-americanismo y la que estudia el proamericanismo, siendo la primera tendencia la que más interés ha suscitado entre la academia. A continuación ofrecemos una breve radiografía de esta discusión.

\section{Anti-americanismo}

El anti-americanismo, que puede entenderse como "la tendencia psicológica a mantener una visión negativa de los Estados Unidos y de la sociedad americana en general", ${ }^{9}$ ha sido ampliamente investigado. Existe un consenso general de que América Latina constituye un caso particular para estudiar este fenómeno, ya que el origen de dicho sentimiento puede hallarse en la región, ${ }^{10}$ donde sobresale como un componente visceral que no se observa en otras partes del mundo.

Un primer grupo de aproximaciones ha investigado el fenómeno desde una perspectiva histórica, tratando de identificar ciclos de mayor y menor intensidad desde el siglo xix hasta la primera década del siglo xxi. Según Greg Grandin ${ }^{11}$ existen dos grandes olas. La primera se presentó a finales del siglo xıx y principios del xx, cuando Estados Unidos inició una etapa de expansión

${ }^{7}$ Véase Julia E. Sweig, Friendly Fire, Nueva York, Public Affairs, 2006.

${ }^{8}$ Robert O. Keohane y Peter J. Katzenstein, "Introduction: The Politics of Anti-Americanisms", en Peter J. Katzenstein y Robert O. Keohane (eds.), AntiAmericanisms in World Politics, Ithaca, Cornell University Press, 2007, pp. 1-9.

${ }^{9}$ Katzenstein y Keohane, "Varieties of Anti-Americanism: A Framework", p. 12.

${ }^{10}$ Sweig, Friendly Fire..., pp. 2-30.

${ }^{11}$ Greg Grandin, "The Narcissism of Violent Differences", en Andrew Ross y Kristin Ross (eds.), Anti-americanism, Nueva York, New York University Press, 2004, pp. 17-31. 
territorial y económica, expresada en situaciones como la guerra con México, la guerra Hispano-Americana y las ocupaciones de Haití y República Dominicana. El resentimiento de las élites políticas y los grupos nacionalistas duró hasta los años treinta, cuando la implementación de la Política del Buen Vecino y el Frente Popular, alinearon a las fuerzas de derecha e izquierda de la región contra la expansión fascista. La segunda etapa inició con el derrocamiento de Jacobo Árbenz en Guatemala en 1956 y la Revolución Cubana de 1959. En ese momento, el anti-americanismo no sólo se justificaba por la serie de intervenciones hechas en América Latina para detener la expansión del comunismo, sino que también crecía la percepción de Estados Unidos como un obstáculo para el desarrollo económico y la consolidación de la democracia. ${ }^{12}$ Otros autores como Julia Sweig ${ }^{13}$ y Luis Fernando Ayerbe ${ }^{14}$ se han enfocado en el desarrollo del anti-americanismo latinoamericano después del año 2000, partiendo de hitos como la aparición de la "nueva izquierda", la invasión a Iraq y la guerra mundial anti-terrorista.

Dentro de los análisis históricos existen también estudios de caso nacionales que permiten observar el desarrollo del anti-americanismo en países específicos, matizando la idea de un sentimiento único y homogéneo en la región. Por ejemplo, McPherson ${ }^{15}$ analiza los casos de Cuba, Panamá y República Dominicana durante los años sesenta. Otros países y sub-regiones de América Latina también han sido examinados como focos de anti-americanismo, incluyendo a México, Colombia, Argentina, Venezuela, Chile, Brasil, Centroamérica y el Cono Sur. En su mayoría, los autores hacen reconstrucciones similares de aquellos eventos y políticas que llevaron al desarrollo de percepciones negativas sobre Estados Unidos, afirmando que la antipatía hacia Washington se deriva de su política exterior y de la conducción

12 Grandin, "The Narcissism of Violent Differences”, p. 20.

${ }^{13}$ Sweig, Friendly Fire..., pp. 148-170.

${ }^{14}$ Luis Fernando Ayerbe, "Antiamericanismo en América Latina: Percepciones y realidades”, Anuario de Integración Latinoamericana y del Caribe, vol. 1, 2007, pp. 100-105.

15 Alan McPherson, Yankee No! Anti-Americanism in U.S.-Latin American Relations, Cambridge, Harvard University Press, 2003. 
de las relaciones bilaterales con cada uno de esos países, lo que sugiere que también se concibe el origen de la identidad en la interacción entre Estados.

Las percepciones y los imaginarios de otros actores sociales también han sido tomadas en cuenta, aunque en menor medida que la de las élites políticas. Por ejemplo, en uno de sus múltiples trabajos sobre América Latina, McPherson ${ }^{16}$ analiza el papel de los actores no estatales dentro de esta tradición, los cuales han visto en la presencia estadounidense una amenaza al proceso de construcción nacional. Otros investigadores han discutido sobre la presencia de este sentimiento en los intelectuales latinoamericanos. ${ }^{17} \mathrm{~A}$ diferencia de los estudios regionales y de caso, esta forma de aproximarse al fenómeno permite entender que al anti-americanismo no se limita al ámbito de la política, sino que puede entenderse como un fenómeno cultural ligado a la construcción de la identidad nacional y regional.

A pesar de sus variaciones, se puede concluir que la literatura académica sobre anti-americanismo comparte dos rasgos comunes. En primer lugar, mantiene una aproximación histórica hacia el fenómeno, concentrándose en la narración de distintos episodios y coyunturas desde comienzos del siglo xx hasta los acontecimientos más recientes que tienen como protagonistas a los gobiernos de la "nueva izquierda" latinoamericana. En segundo, existe la tendencia de tomar como objeto de estudio las percepciones de las élites, sean políticas, económicas o culturales, con lo cual el anti-americanismo se analiza exclusivamente desde posiciones hegemónicas.

16 "Anti-americanism in Latin America and the Caribbean. False Populismo or Coming Full Circle”, en Ivan Krastev y Alan McPherson (eds.), The Anti-American Century, Budapest, European University Press, 2007, pp. 49-75.

17 Véase Michael Radu, "A Matter of Identity: The Anti-Americanism of Latin American Intellectuals”, en Paul Hollander (ed.), Understanding Anti-Americanism: Its Origins and Impact at Home and Abroad, Chicago, Ivan R. Dee, 2004, pp. 144-164; Mary Louise Pratt, "Back Yard with Views", en Andrew Ross y Kristin Ross (eds.), Anti-americanism, Nueva York, New York University Press, 2004, pp. $32-45$. 


\section{Pro-americanismo}

El pro-americanismo, entendido como la tendencia psicológica a mantener una visión positiva de Estados Unidos y de la sociedad americana, ha sido poco estudiado a nivel mundial, ${ }^{18}$ tal vez por considerarse la "norma" frente a la que el anti-americanismo presenta una desviación. Existen algunos trabajos que hacen un barrido general sobre la presencia de sentimientos pro-americanos en diferentes países, y otros en donde se ahonda en casos nacionales que tradicionalmente han sido aliados de Estados Unidos. ${ }^{19}$

Andy Baker y David Cupery ${ }^{20}$ buscan desmentir la idea de que en América Latina ha dominado un sentimiento anti-americano después del 11 de septiembre de 2001, señalando que en su lugar, lo que se observa en la región es un intenso pro-americanismo producto del intercambio económico. Para probar esta hipótesis, los autores van más allá de las élites y retoman la encuesta Latinobarómetro, tomando cuatro dimensiones del intercambio económico, a saber, importaciones, exportaciones, ayuda exterior y migración. Encuentran que el promedio de los ciudadanos de la región tiene una percepción favorable de Estados Unidos, la cual se deriva principalmente de las importaciones o del consumo de bienes estadounidenses.

Otros datos de Latinobarómetro sugieren que la migración, las exportaciones y la ayuda exterior no tienen mayor influencia sobre las percepciones que se tienen de Estados Unidos.

18 Anne Applebaum, "In Search of Proamericanism”, Foreign Policy, 1 de julio de 2005, pp. 34-35.

${ }^{19}$ Véase Seong Wong Park, "The Present and Future of Americanization in South Korea”, Journal of Futures Studies, vol. 14, núm. 1, 2009, pp. 51-66; Philip Bell y Roger Bell, "Americanization: Political and Cultural Examples from the Perspective of 'Americanized' Australia”, American Studies, vol. 37, núm. 1, 1996, pp. 1-21; Osvaldo Croci, "The ‘Americanization' of Italian Foreign Policy?”, Journal of Modern Italian Studies, vol. 10, núm 1, 2007, pp. 10-26; Tsurumi Yoshiyuki, “Americanism in Postwar Japan: Political Consciousness on Pro/Anti-American Sentiment", AJ Forum 10, 2007.

${ }^{20}$ Baker y Cupery, “Anti-Americanism in Latin America....”, pp. 106-130. 
Además, los resultados de Cupery y Baker demuestran que el legado imperialista de la política exterior estadounidense no tiene ningún efecto sobre la imagen que ha construido la opinión pública latinoamericana de ese país. En este sentido, este trabajo contradice el argumento que ha formulado la mayoría de los estudios históricos sobre anti-americanismo, de que el odio hacia Estados Unidos se deriva de lo que hace, es decir, de su política exterior.

Si a nivel regional los análisis han sido pocos, los estudios de caso nacionales son casi inexistentes. Es posible que el análisis de William O. Walker ${ }^{21}$ de Colombia sea el único trabajo sobre un país latinoamericano donde se habla de un anti-americanismo "silencioso" y la simultánea presencia de percepciones positivas fuertes respecto a Estados Unidos. El autor sostiene que aunque hubo varias posiciones hostiles hacia la política de drogas que Washington manejaba hacia Colombia desde los años ochenta, la difícil situación por la que pasaba el país provocó una convergencia bilateral en los intereses de seguridad y el desarrollo de una cultura política común, lo que generó una imagen más favorable acerca de Estados Unidos.

\section{Limitaciones de los trabajos sobre anti- y pro-americanismo}

Esta breve revisión sugiere que existe un universo de trabajos sobre las percepciones negativas y positivas que se tiene de Estados Unidos en América Latina, aunque presenten algunas limitaciones. La mayoría de los trabajos sostiene la tesis de un ferviente anti-americanismo en América Latina en función del comportamiento de actores con alto perfil público, tales como los líderes de Estado, políticos, caudillos, élites económicas e intelectuales, por lo que podría afirmarse que prima una lectura Estado-céntrica

21 William O. Walker III, "The United States, Colombia, and Drug Policy, 1984-2004. A Study Of Quiet Anti-Americanism”, en Alan McPherson (ed.), AntiAmericanism in Latin America and the Caribbean, Nueva York, Berghahn Books, 2006, pp. 239-270. 
en la que los discursos y las políticas de los actores estatales son la prueba empírica de la existencia de un resentimiento regional hacia Estados Unidos. No obstante, esta aproximación es problemática en la medida en que asume que el antiamericanismo que profesan algunas élites es compartido por las masas. ${ }^{22}$

Aunque existen unas pocas investigaciones sobre el anti-americanismo que incorporan a la opinión pública, ${ }^{23}$ las preguntas sobre las que fundamentan sus hallazgos no permiten captar la complejidad de este fenómeno identitario, como por ejemplo en los casos de: “¿Cuál es su opinión sobre Estados Unidos?”; “¿Cuál es su opinión sobre el presidente de Estados Unidos?”; “Chonfía en el gobierno de Estados Unidos?”; “¿Considera que el gobierno estadounidense es amigo o enemigo de su gobierno nacional?". Si bien estas preguntas ayudan a acercarnos a las percepciones de la población general, no permiten evaluar otros aspectos de la imagen de Estados Unidos, conque no ofrecen suficiente evidencia empírica para afirmar que prima un sentimiento anti-americano en América Latina.

Finalmente, la forma holista en la que suele hablar del antiamericanismo es cuestionable. Se acostumbra hablar del anti-americanismo en singular, como si fuera una identidad homogénea que cobijara todas las facetas de la percepción que existe sobre Estados Unidos, mientras que, por el contrario, lo que puede observarse en los datos de Las Américas y el Mundo es que hay dimensiones que pueden incitar rechazo y otras que pueden suscitar aprobación. De esta manera, es necesario matizar la idea del antiamericanismo en singular y desagregarlo con el fin de identificar

22 Baker y Cupery, “Anti-Americanism in Latin America...”, pp. 106-130; George Yudice, "U.S. Prepotencia. Latin Americans Respond”, en Andrew Ross y Kristin Ross (eds.), Anti-americanism, Nueva York, New York University Press, 2004, pp. 69-8.

23 Véase McPherson "Anti-americanism in Latin America and the Caribbean...", pp. 49-75; Justice Lance, "Populism and Anti-Americanism in Modern Latin America", Origins: Current Events in Historical Perspective, vol. 1, núm. $1,2007$. 
las distintas dimensiones que causan sentimientos negativos o positivos.

\section{Constructivismo de sentido común}

El constructivismo, a diferencia de teorías como el neorrealismo y el neoliberalismo, ofrece herramientas útiles para estudiar las identidades de los actores estatales, entre ellas el anti y pro-americanismo. La identidad puede entenderse como un conjunto de significados que un actor atribuye a sí mismo, pero que a su vez son moldeados por su interacción social con otros actores. ${ }^{24}$ Para el constructivismo, la importancia de las identidades se halla en que constituyen la base para entender qué quieren en la escena internacional.

Pese a ello, según Ted Hopf, ${ }^{25}$ la agenda constructivista ha tenido una limitante importante: no explica el papel de las masas en la construcción social de la identidad. Al enfocarse en la interacción entre Estados en el sistema internacional, el constructivismo ignora el rol que los actores internos, ya sean las masas o la élite, juegan en la formación de la identidad. ${ }^{26}$ Este vacío ha sido trabajado por las aproximaciones constructivistas al análisis de la política exterior (FPA), en las cuales la "caja negra" del Estado se abre para determinar cuáles son los actores domésticos que participan en el proceso de toma de decisiones, y en últimas, en la generación de los pilares de la identidad estatal. Según Jutta Weldes, ${ }^{27}$ la forma como un Estado interactúa en el sistema internacional está determinada por la identidad que los políticos han construido previamente en el escenario doméstico por efecto de un proceso de co-constitución entre distintos actores con múltiples imágenes

${ }^{24}$ Véase Alexander Wendt, "Collective Identity Formation and the International State”, The American Political Science Review, vol. 88, núm 2, 1994, pp. 384-396.

${ }^{25}$ Véase Hopf, “Common-sense Constructivism....", pp. 317-354.

26 Ted Hopf, "The Promise of Constructivism in International Relations Theory”, International Security, vol. 23, núm. 1, 1998, pp. 194-195.

${ }^{27}$ Jutta Weldes, "Constructing National Interests", European Journal of International Relations, vol. 2, núm. 3, 1996, pp. 275-318. 
de país. En esta misma línea, Martha Finnemore y Kathryn Sikkink ${ }^{28}$ hablan del rol de los "empresarios de normas" y Jeff Chec$\mathrm{kel}^{29}$ del papel de los académicos en la construcción de la identidad. A pesar de complementar al constructivismo sistémico, trabajos como estos caen en el inconveniente de estudiar solamente el papel de distintas élites, sin tomar en consideración el "sentido común" de la población.

Una forma de incluir a la sociedad dentro del constructivismo y, por extensión, al análisis sobre el anti y pro-americanismo, es a través del common-sense constructivism desarrollado por Hopf,,${ }^{30}$ cuya meta es involucrar a las masas en el estudio de las relaciones internacionales, al plantear que las identidades de los Estados no son resultado único y exclusivamente de lo que hacen las élites, sino que en ese proceso también intervienen otros sectores sociales.

La noción de sentido común utilizada por Hopf hace referencia al mismo concepto empleado por Antonio Gramsci, quien lo describe como un conjunto de conocimientos que son "el resultado de procesos históricos de sedimentación cultural, el residuo de una multitud de depósitos, fragmentarios y contradictorios, abiertos a múltiples interpretaciones y que sirve como apoyo de diferentes tipos de visiones sociales y proyectos políticos. Este sistema de pensamiento representa una variedad acumulada de diversos tipos de creencias derivadas de la mitología y el folklore, la religión, versiones populares de las doctrinas filosóficas y científicas, y así sucesivamente". 31

Ahora bien, la superación de una visión Estado-céntrica no es la única ventaja que ofrece el constructivismo de sentido común. Los trabajos reseñados también abordan el fenómeno en singular y de forma homogénea, con excepción del estudio de Baker y

${ }^{28}$ Martha Finnemore y Kathryn Sikkink, "International Norm Dynamics and Political Change”, International Organization, vol. 52, núm. 4, 1998, pp. 887-917.

${ }^{29}$ Jeff Checkel, "Ideas, Institutions, and the Gorbachev Foreign Policy Revolution”, World Politics, vol. 45, núm. 2, 1993, pp. 271-300.

${ }^{30}$ Véase Hopf, “Common-sense Constructivism....", pp. 317-354.

${ }^{31}$ Mark Rupert, “Gramsci”, en Jeny Edkins y Nick Vaughan-Williams (eds.), Critical Theorists and International Relations, Nueva York, Routledge, 2009, p. 183. 
Cupery, ${ }^{32}$ en el que si bien se analiza el sentido común, se enfatiza en las dimensiones económicas del pro-americanismo, dejando por fuera aspectos políticos y culturales que pondrían en entredicho la idea de países con sólidas identidades pro y anti-americanas. $\mathrm{Al}$ introducir el concepto de sentido común, pretendemos ampliar el universo a aspectos políticos, sociales y culturales de la percepción que se tiene de Estados Unidos, con lo cual la complejidad de las identidades regionales respecto a ese país se pondrá de relieve.

\section{Metodología y datos}

Aunque Hopf utiliza libros de texto sobre historia y novelas para operacionalizar el sentido común de las masas en el caso de Rusia, estos no son los únicos instrumentos disponibles para observar la forma en la que piensan las personas. Según el mismo autor, las encuestas nacionales son herramientas de gran utilidad, ya que permiten validar afirmaciones a partir de muestras representativas. ${ }^{33}$ Dicho de otro modo, las encuestas de opinión pública son una forma de representar un concepto tan abstracto como lo es el sentido común.

El sentido común hace referencia a un conocimiento, a una visión de la realidad que se caracteriza por ser estable, organizado, racional y sólido, características que también se pueden encontrar en la opinión pública. Tradicionalmente, en los estudios sobre opinión pública y política exterior predominó el consenso AlmondLippman, según el cual la opinión pública es volátil e incoherente, por lo cual es muy difícil que tenga impacto en la política exterior; ${ }^{34}$ sin embargo, varias investigaciones ${ }^{35}$ han concluido que el público

${ }^{32}$ Véase Baker y Cupery, “Anti-Americanism in Latin America...”, pp. 106-130.

${ }^{33}$ Hopf, "Common-sense Constructivism”, p. 350.

${ }^{34}$ Véase Jerel A. Rosati y James C. Scott, The Politics of the United States Foreign Policy, Boston, Wadsworth, 2011.

35 Véase Ole R. Holsit, "Public Opinion and Foreign Policy: Challenges to theAlmond-Lippmann Consensus”, International Studies Quarterly, vol. 36, núm. 4, 1992, pp. 439-466; Jeffrey W. Knopf, "How Rational Is the Rational Public? Evidence from U.S. Public Opinion on Military Spending", The Journal of Conflict Resolution, vol. 42, núm. 5, 1996, pp. 544-571; Bruce W. Jentleson, "The Pretty Prudent 
en general sostiene actitudes estables, estructuradas y racionales sobre los asuntos internacionales, por lo que puede convertirse en una fuerza determinante para la conducción de la política exterior.

En resumen, es posible afirmar que la opinión pública, en el caso de hallar tendencias consistentes, puede expresar las bases de un determinado sentido común. En aras de operacionalizar este concepto, las encuestas aparecen como una herramienta útil, por lo que en el caso específico de este artículo, daremos una mirada al sentido común de las masas latinoamericanas respecto a Estados Unidos, mediante los resultados de las encuestas que hacen parte del proyecto Las Américas y el Mundo. A diferencia de otros estudios de opinión pública en América Latina, los datos que ofrece este proyecto son particularmente útiles para este trabajo. En primer lugar, porque al ser una encuesta dirigida principalmente al análisis de la política exterior, las preguntas permiten relacionar el anti y pro-americanismo con la política internacional de los países. En segundo lugar, otras encuestas no manejan un pool de preguntas sobre Estados Unidos y Latinoamérica lo suficientemente grande y variado como para tener un panorama amplio sobre los sentimientos y percepciones que tiene la gente al respecto. Finalmente, en el proyecto de Las Américas y el Mundo hay mucha continuidad y consistencia en cuanto a las preguntas que se hacen en cada país, lo cual es fundamental para poder afirmar que lo que hay entre la opinión pública es un common sense y no una serie de apreciaciones esporádicas.

Estas encuestas se realizaron en 2008, 2010 y 2012 en diferentes grupos de países, incluyendo datos de población urbana y rural. En 2008 participaron Perú (1 235 entrevistados), México (2400), Colombia (1500) y Chile (1574). En 2010, los países participantes fueron Ecuador (1574), Brasil (2400), Perú (1516), Colombia (1500) y México (2400). En 2012 la encuesta se realizó en México (2400), Ecuador (1503) y Colombia (1699).

Debido a que nuestro objetivo principal es dibujar la imagen que se tiene de Estados Unidos, sólo utilizamos aquellas preguntas

Public: Post Post-Vietnam American Opinion on the Use of Military Force", International Studies Quarterly, vol. 36, núm. 1, 1992, pp. 49-73. 
de cada encuesta que se relacionan directa o indirectamente con ese país. En total identificamos dieciséis preguntas a lo largo de los tres cuestionarios, que si bien no fueron aplicadas en todos los países para cada año analizado, es posible afirmar que ofrecen suficiente información como para construir un marco de percepciones. Las preguntas, pese a su diversidad, se organizaron en dos categorías: percepciones generales sobre Estados Unidos y percepciones sobre la relación de Estados Unidos con América Latina.

\section{SENTIMientos Generales hacia Estados Unidos}

La opinión pública y los tomadores de decisiones tienen creencias e imágenes básicas sobre otros Estados que aparecen como una variable fundamental del proceso de toma de decisiones, pues reduce los niveles de incertidumbre a la hora de formular la política exterior. En el caso de América Latina no existe una imagen homogénea sobre Estados Unidos; es posible encontrar temas sobre los cuales hay una mayor reticencia hacia el alineamiento con este país, mientras que hay otros en los que se privilegia la cooperación, por lo que no es posible arrojar afirmaciones concluyentes sobre cómo se construye el sentido común de los latinoamericanos y por qué se presentan variaciones entre la opinión pública.

Estados Unidos: ¿̨imagen positiva o negativa?

$\mathrm{Al}$ indagar por la opinión sobre Estados Unidos en una escala que va de 0 a 100 , donde entre más alto es el valor más positiva es la imagen, es posible encontrar posiciones diversas. Brasil (52) y Chile (53) son los países que tienen las cifras de aceptación más bajas. En México, Ecuador y Perú el porcentaje de favorabilidad siempre ha sido mayor a 60, y en Colombia, durante 2008, 2010 y 2012 esta cifra ha sido superior a 70 (véase la gráfica 1). A pesar de no existir una percepción unificada, es posible señalar que en México, Perú, Ecuador y Colombia, la imagen positiva de Estados Unidos ha aumentado con el tiempo, especialmente en los primeros dos países. 
Gráfica 1

Calificación de Estados Unidos

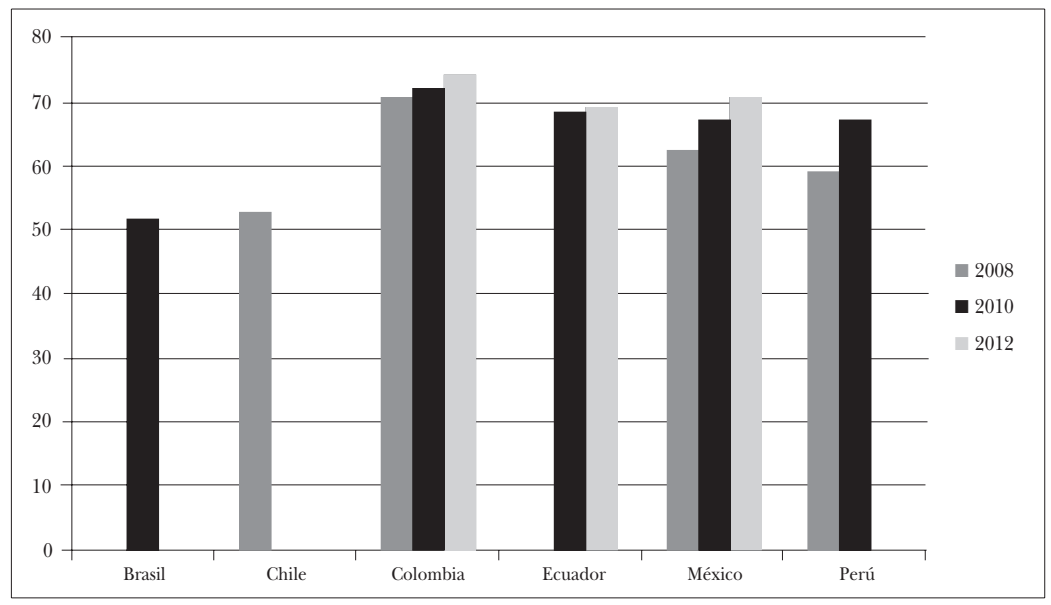

Podría argumentarse que la percepción que se tiene de Estados Unidos está mediada por una serie de sentimientos más específicos como admiración/desprecio (gráfica 2a) y confianza/desconfianza (gráfica 2b), a partir de los cuales se puede afirmar que en el sentido común de los latinoamericanos prima una imagen estadounidense positiva. En los seis casos prevalece un sentimiento de admiración, con niveles de indiferencia que no superan el 34\% de la población en ninguno de ellos. El sentimiento de desprecio es el más bajo respecto a los otros dos, oscilando entre 3 y $28 \%$. No obstante, es importante subrayar los altos porcentajes de desprecio hacia Estados Unidos mostrados en México (29\%) y Chile (28\%) en 2008, lo cual, a manera de hipótesis, podría estar relacionado a los posibles impactos de la crisis financiera en sus respectivas sociedades.

\section{Desconfianza a pesar de la admiración}

A pesar de los altos niveles de admiración, la desconfianza hacia Estados Unidos es considerable en algunos países, lo cual sugiere una cierta ambigüedad en la percepción que se tiene de este país. 
Chile, México y Perú constituyen casos paradigmáticos en 2008, donde 53, 61 y $57 \%$ de los encuestados respectivamente manifiestaron sentimientos de desconfianza. Sin embargo, este comportamiento se modifica en las encuestas posteriores en México (45\% en 2010 y $40 \%$ en 2012) y Perú (35\% en 2010), observándose una tendencia hacia el aumento de confianza (véase la gráfica $2 b$ ).

Colombia y Ecuador, por su parte, tienen un comportamiento diferente donde el porcentaje de encuestados que desconfía de Estados Unidos no supera $35 \%$. Al contrario, manifiestan altos niveles de confianza en 2008 (39\% en Colombia), 2010 (54\% en Colombia y 51\% en Ecuador) y 2012 (56\% en Colombia y 47\% en Ecuador). Brasil, por su parte, se muestra como un país con una opinión pública relativamente dividida alrededor del tema en 2010 , con un $41 \%$ de encuestados que confían en Estados Unidos frente a $34 \%$ que desconfían.

GRÁFICA 2a

Sentimientos hacia Estados Unidos (admiración/desprecio)

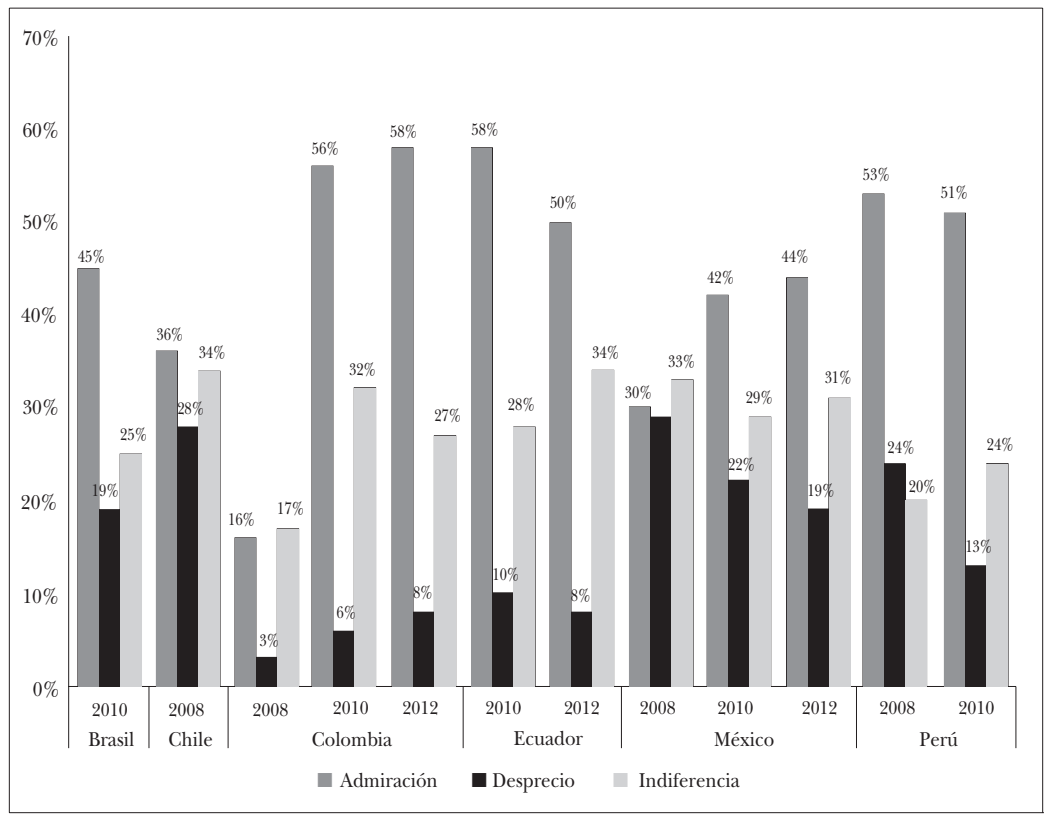


GrÁFICA 2b

Sentimientos hacia Estados Unidos (confianza/desconfianza)

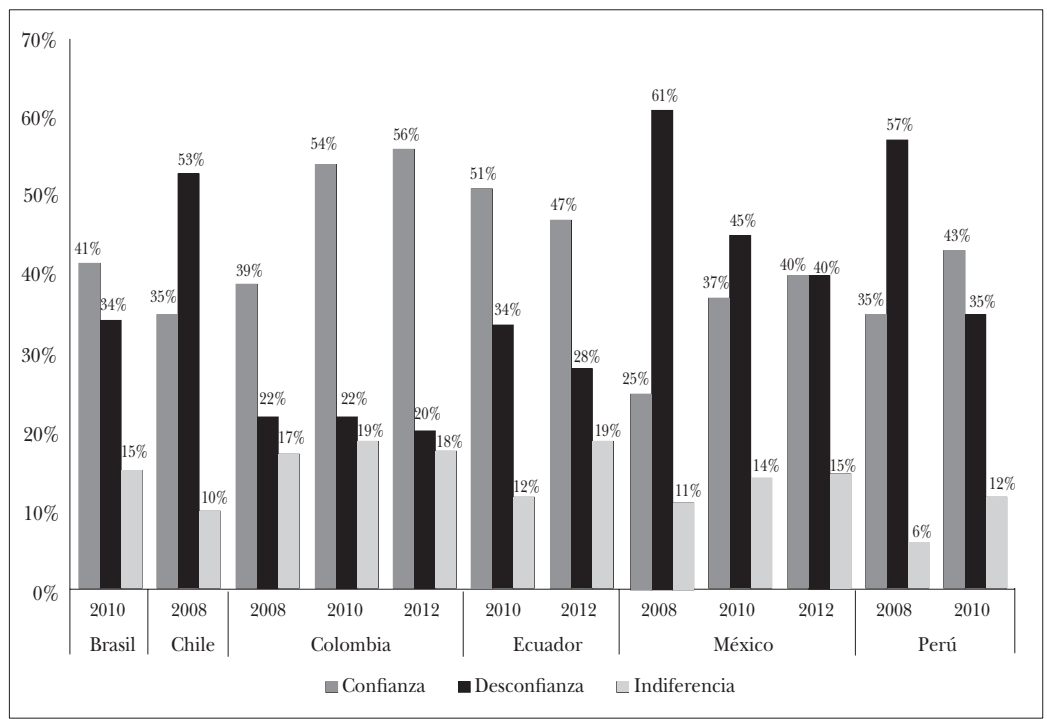

Barack Obama: una imagen mejor para el ejecutivo estadounidense

Otra manera de evaluar la percepción que se tiene de Estados Unidos en América Latina es a través de la opinión que tienen los ciudadanos de su ejecutivo. A los encuestados se les pide que califiquen en una escala de 0 a 100 la imagen que tienen de distintos gobernantes, entre ellos, el presidente de Estados Unidos. Colombia es el país que mejor lo califica en 2008 (57.4), 2010 (70) y 2012 (71.3), seguido por Ecuador en 2010 (64) y 2012 (66), y por México en 2010 (63) y 2012 (64). Aunque en Chile (28) y Brasil (50) ${ }^{36}$ no es posible observar la evolución en el tiempo, los resultados de estos países señalan que hay una percepción menos negativa en el caso del segundo.

${ }^{36}$ En el caso de Brasil, en 2010 se preguntó por George W. Bush, mientras que en los otros países fue por Barack Obama. 
Entre 2008 y 2010 el presidente demócrata Barack Obama reemplazó a George W. Bush, un líder poco apreciado en la región, con lo que hubo cambios en Colombia, México y Perú. La salida de Bush representó un cambio positivo en la imagen que se tenía del ejecutivo estadounidense. En Perú, la calificación pasó de 42 en 2008 a 61 en 2010, en México de 45 a 63 y en Colombia de 57 a 70.

Percepciones Sobre la Relación de Estados Unidos con América Latina

En general, los latinoamericanos tienden a valorar la relación de sus países con Estados Unidos en términos positivos. En 2008 la mayoría de los chilenos $(55 \%)$, colombianos $(52 \%)$, mexicanos $(51 \%)$ y

GRÁFICA 3

Calificación de la relación con Estados Unidos. Colombia, Ecuador y México 2012

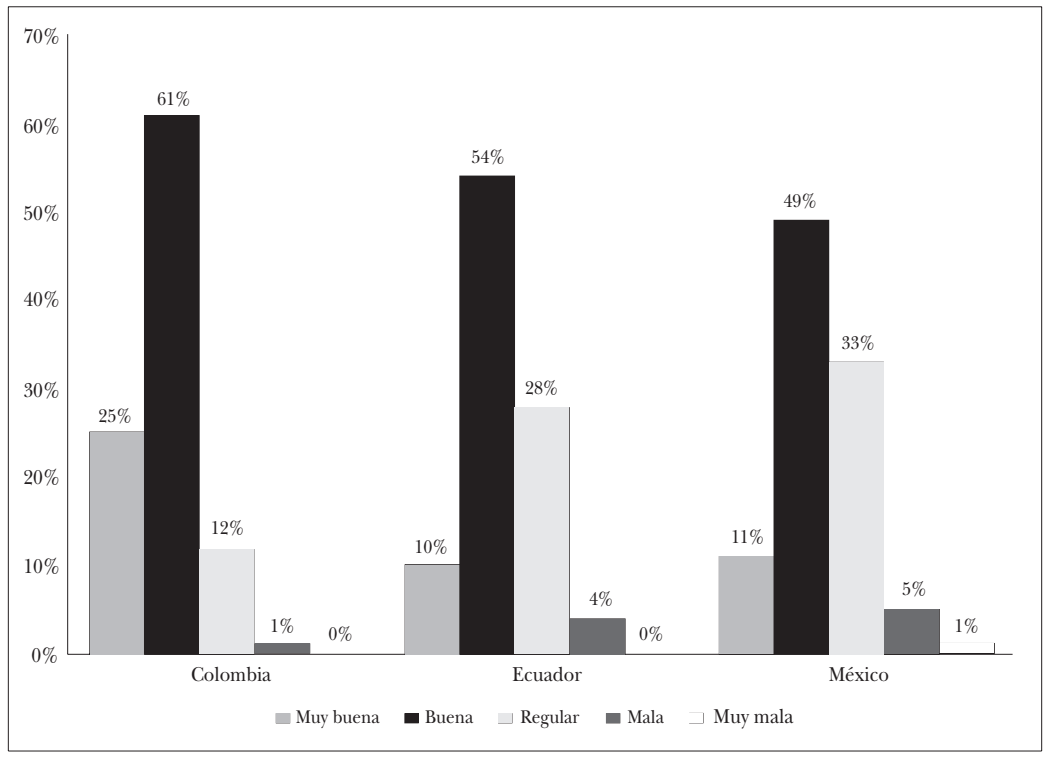


peruanos (42\%) afirmaron que la relación de sus países con la Casa Blanca respondía a la condición de socios; porcentajes menores, pero igualmente significativos, describieron esta relación en términos de amistad: $32 \%$ en Chile, $41 \%$ en Colombia, $28 \%$ en México y $40 \%$ en Perú. Las percepciones negativas, por su parte, son menores en todos los casos, lo que sugiere que no hay una orientación anti-americana por parte de los encuestados en esta materia.

En la misma línea, los encuestados consideran que sus países tienen buenas relaciones con Washington. De acuerdo con datos de 2012, $86 \%$ de los colombianos, $64 \%$ de los ecuatorianos y $61 \%$ de los mexicanos las califican al menos como buenas, frente a porcentajes de 12, 28 y 33\%, respectivamente, que las califican como regulares (véase la gráfica 3).

\section{La importancia de Estados Unidos}

En 2012 encontramos una tendencia a calificar como muy importante la relación de sus países con Estados Unidos en Colombia, Ecuador y México. Colombia es el país donde se asigna mayor importancia

\section{GRÁFICA 4}

Importancia de la relación con Estados Unidos. Colombia, Ecuador y México 2012

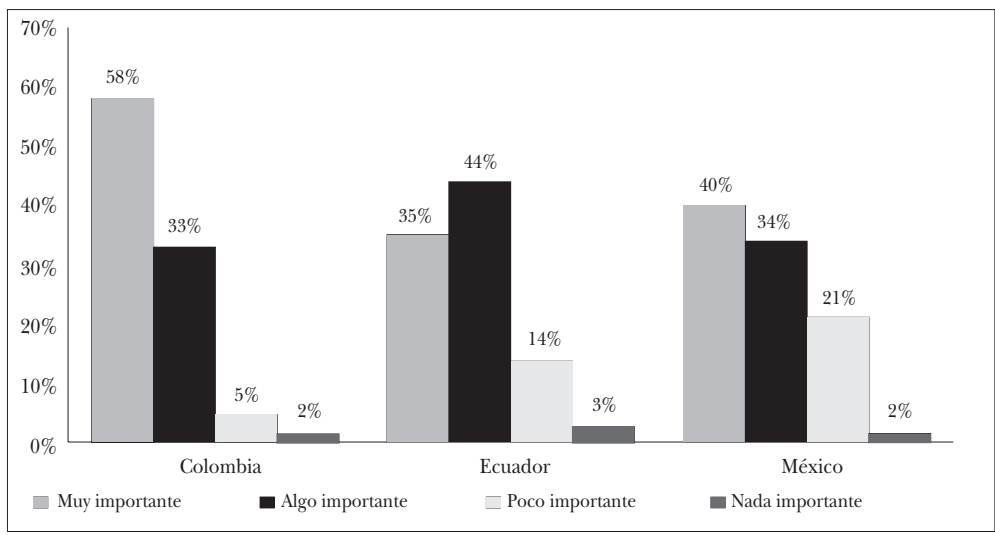


a la relación bilateral con un $91 \%$ de los encuestados que afirman que es por lo menos algo importante, mientras que para los casos de Ecuador y México se observa una disminución de esta percepción con 74 y $79 \%$ respondiendo en la misma línea. Sin embargo, es importante destacar estos dos casos, donde existen porcentajes relativamente significativos de encuestados que consideran que la relación con Estados Unidos es poco o nada importante $(17$ y $23 \%$ respectivamente), mientras que en Colombia no superan el $7 \%$ (véase la gráfica 4).

\section{Trabajo cercano y cooperación}

En 2008 se pidió a los encuestados de Chile, Colombia y México que evaluaran la cercanía de sus respectivos países con el gobierno estadounidense en una escala de 0 a 10 , donde 0 suponía trabajar prácticamente solos y 10 trabajar muy cerca de este último. Como se puede apreciar en la gráfica 5 , hay una tendencia hacia la preferencia de un trabajo con Estados Unidos, sin que ello signifique una cercanía o un alineamiento total.

No obstante, esa aprobación se matiza al plantearse situaciones en las que los países latinoamericanos deban asumir tareas o compromisos que no sean de su total agrado. En 2008 la mayoría de los encuestados de Colombia (57\%) y México (61\%) manifestó su desacuerdo ante la posibilidad de que sus países asumieran compromisos que no les gustan en aras de resolver problemas comunes mediante decisiones conjuntas con Estados Unidos. En ambos casos, sólo 25 y $24 \%$ respectivamente estuvieron de acuerdo con la premisa, y $14 \%$ en el caso de Colombia y un $9 \%$ afirmaron que eso dependería de la situación.

En 2010, contando con datos de Colombia, Ecuador, México y Perú, se mantiene la misma tendencia. Podemos afirmar que, en promedio, el $54 \%$ de los encuestados en los cuatro países está en desacuerdo con que su país deba asumir compromisos que no le gusten para trabajar con Washington en la solución de problemas comunes; el 31\%, por el contrario, está de acuerdo, mientras que 
el 11\% afirma que su posición dependerá de la situación particular sobre la que se trabaje.

GRÁFICA 5

Trabajar cerca de Estados Unidos. Chile, Colombia

y México 2008

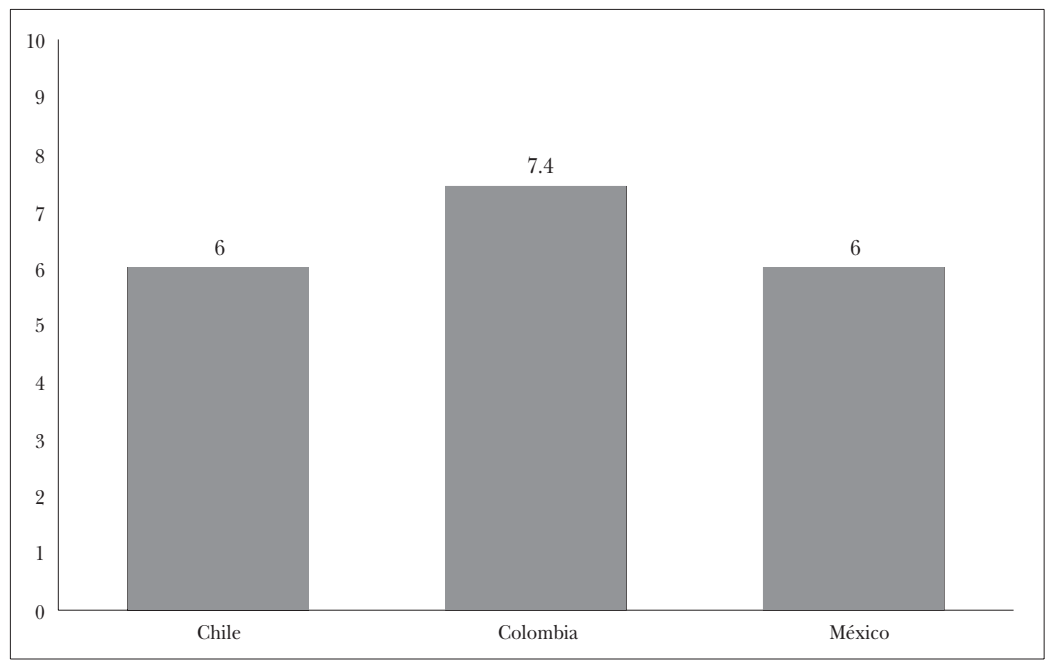

En 2012 se vuelve a indagar por este tema, pero únicamente en Colombia y México, donde se mantiene la misma tendencia, aunque con una leve disminución en los porcentajes de quiénes se muestran en desacuerdo con la idea de asumir compromisos que no les gusten; en el caso de Colombia se desciende hasta $47 \%$, mientras que en el caso de México se llega sólo hasta 54\%, como se puede observar en la siguiente gráfica.

A partir de esto es posible sugerir que el anti-americanismo no es un asunto preconcebido entre los latinoamericanos, sino que por el contrario aparece cuando hay una amenaza de mayor intervención por parte de Estados Unidos o de acciones que impliquen una cesión, aunque sea parcial, de soberanía. 


\section{GRÁFICA 6}

Decisiones conjuntas y compromisos con Estados Unidos.

Colombia y México 2008, 2010 y 2012

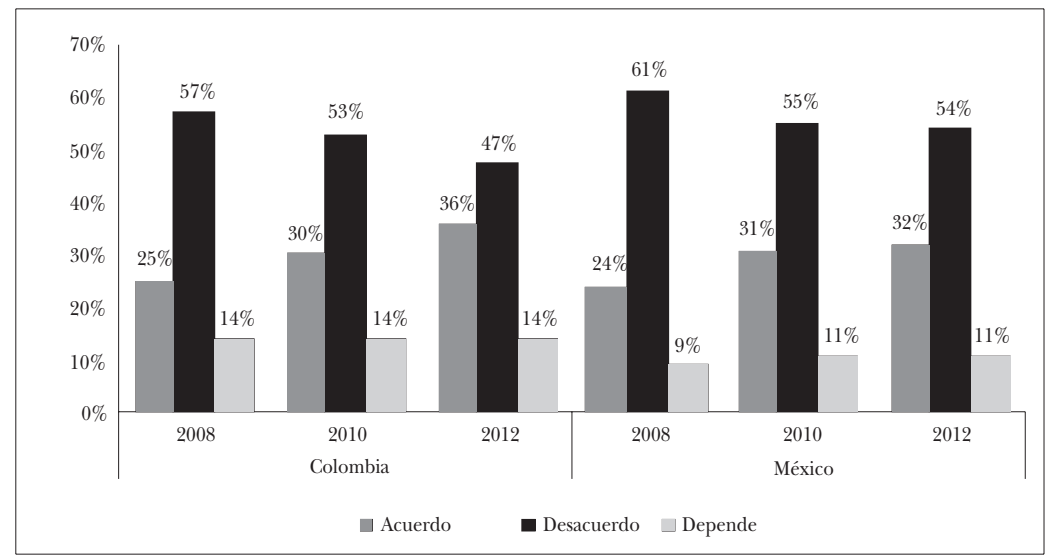

¿Con América Latina o con Estados Unidos?

Tomando en consideración que los países de la región se han movido entre la búsqueda de una relación privilegiada con Estados Unidos y la consolidación de bloques regionales para defender sus intereses frente a este último, en 2010 se indagó por la percepción de la opinión pública en Colombia, Ecuador, México y Perú en ese sentido. Frente a ello, se pueden mostrar algunas tendencias en la opinión pública de los cuatro países que dan cuenta de un panorama heterogéneo, a partir del cual es complicado hacer afirmaciones concluyentes con respecto a sentimientos de pro o anti-americanismo fuertemente arraigados en el sentido común latinoamericano. En el caso de Colombia la mayoría de los encuestados $(54 \%)$ considera que su gobierno debe buscar un trato preferencial por parte de Estados Unidos, independientemente de su relación con el resto de países de América Latina, mientras que sólo el $31 \%$ cree que se debe privilegiar la coordinación con los demás países de la región para defender sus intereses frente a este último. 
La opinión pública de Ecuador y México, por su parte, se encuentra relativamente dividida. El 40 y el $49 \%$, respectivamente, creen que se debe buscar un trato preferencial estadounidense, frente a 38 y $37 \%$ que preferirían una coordinación con el resto de países de la región. Los encuestados peruanos, por el contrario, privilegian la conformación de bloques regionales para defender sus intereses $(41 \%)$ por encima de la búsqueda de un trato preferencial $(35 \%)$.

En 2012 se observan algunos cambios en los casos de Colombia y Ecuador. Los encuestados colombianos matizaron un poco su opinión: el $41 \%$ se mantiene en la posición de buscar un trato privilegiado con Washington y el $25 \%$ se muestra favorable a coordinar posiciones con el resto de América Latina, mientras que para el 19\% dependerá de la situación particular. En el caso de Ecuador la balanza se inclina un poco más hacia la coordinación de bloques latinoamericanos $(39 \%)$ que hacia la búsqueda de privilegios con Estados Unidos (37\%). México, por su parte, mantiene la misma tendencia de la encuesta anterior: el $45 \%$ se inclina hacia la búsqueda de un trato especial de Estados Unidos y el 36\% lo hace hacia la coordinación con el resto de América Latina. En ninguno de los tres casos es posible hablar de una tendencia hacia el pro o el anti-americanismo, pero sí es posible evidenciar una coherencia entre las decisiones tomadas por sus respectivos gobiernos de acercamiento hacia los países de la región.

Evaluación de las distintas dimensiones de la relación Estados Unidos-América Latina

Una manera de evaluar el desempeño de Estados Unidos y la percepción que se tiene de éste en la opinión pública latinoamericana es de acuerdo a su política exterior. En 2012 se pide a los encuestados de Colombia, Ecuador y México que califiquen la actuación estadounidense en siete áreas específicas en una escala de 1 a 7 , siendo 1 muy negativa y 7 muy positiva: América Latina, Cuba, México, el combate contra el terrorismo mundial, la defensa de la 
democracia en el mundo, la promoción del libre comercio y el envío de tropas militares en situaciones de conflicto.

De los siete temas evaluados, el que obtuvo mayor rechazo fue la actuación estadounidense en Cuba: los colombianos le asignan 3.4, los ecuatorianos 3.6 y los mexicanos 3.8. Aunque la diferencia no es significativa, es llamativo que Colombia sea el país que presenta mayor rechazo y México el que menor, si se tienen en cuenta las relaciones bilaterales de estos dos países con Cuba y las percepciones que se tienen sobre esta última y sus líderes. Colombia mantuvo una política exterior conflictiva hacia Cuba durante la Guerra Fría, fruto del conservadurismo de su élite política y de los supuestos nexos entre el régimen cubano y los actores armados colombianos; sin embargo, desde la década de 1990 ésta ha sido mucho más cordial aun cuando la percepción general sobre Cuba y sobre Fidel y Raúl Castro sea marcadamente negativa. Por el contrario, México ha sido uno de los aliados más importantes de Cuba desde la Revolución, y con excepción del gobierno de Vicente Fox, ha mantenido una estrecha relación con la isla como pocos países en América Latina, pese a que la mayoría de la opinión pública evalúa el régimen cubano en un punto medio, sin valorarlo en términos marcadamente positivos o negativos.

La siguiente peor evaluación, aunque mucho mejor posicionada que la anterior, fue el envío de tropas militares en situaciones de conflicto. Los tres países otorgan un 4.7 a esta política, lo cual es interesante si se tiene en cuenta que una de las explicaciones sobre el anti-americanismo en la región se relaciona con el legado de intervenciones militares estadounidenses. De igual forma es importante tener en cuenta que México, Colombia y Ecuador no se vieron afectados del mismo modo por ese pasado de intervenciones estadounidenses, por lo que es difícil afirmar que el anti-americanismo de estos países está fundamentado en los agravios que cometieron en el pasado las tropas estadounidenses en sus propios territorios.

En el orden de más baja a más alta calificación, los temas que siguen son: la relación con América Latina y la defensa de la democracia en el mundo. En cuanto al primero, Ecuador y México son más sensibles que Colombia al conceder un 4.8, mientras que 
ésta califica su actuación en la región con un 5.2. Por el contrario, el amparo de los valores democráticos es visto de forma más positiva entre los ciudadanos ecuatorianos (5.1) que los colombianos y mexicanos (4.9).

Las tres políticas evaluadas de manera más positiva corresponden a la promoción del libre comercio, el combate contra el terrorismo mundial y la relación con México. En los tres casos, hay una calificación igual o mayor a 5, aunque es necesario resaltar algunos matices importantes. En primer lugar, no existen diferencias significativas entre la evaluación que hacen los encuestados de México (5.1) y Colombia (5.2), por un lado, y Ecuador, por el otro, de los esfuerzos de Estados Unidos por promover el libre comercio, lo cual es interesante si se tiene en cuenta que los dos primeros tienen tratados de libre comercio con Estados Unidos, mientras que el último presenta una posición bastante reticente frente a ello. Segundo, es llamativo que cuando se trata del combate al terrorismo, los ecuatorianos (5.4) evalúan mejor el rol de Estados Unidos, que los colombianos y mexicanos (5.1); esto es de particular importancia dado que en el caso colombiano Estados Unidos ha sido un aliado directo en la lucha contra los mal denominados "terroristas" locales, por lo que se habría esperado que su lucha global tuviera una mayor acogida entre la población. Por fin, es también sugerente que en Ecuador, un país cuyo gobierno ha sido un ferviente opositor de la intervención estadounidense en Medio Oriente, donde no hay niveles de crimen organizado similares a los mexicanos y colombianos, y que no tiene ningún acuerdo de seguridad similar al Plan Colombia o al Plan Mérida, sea tan bien vista la lucha de Estados Unidos contra el terrorismo global.

Ayuda contra el narcotráfico y el crimen organizado

Otra forma de evaluar el desempeño y la confianza que se tiene de la relación con Estados Unidos es mediante su actuación en temas específicos como la lucha contra el narcotráfico y el crimen organizado en una escala de 1 a 7 . En Colombia, Ecuador y México se considera que el envío de narcotraficantes para que sean juzgados 
en Estados Unidos es una forma eficaz para resolver el problema del narcotráfico: los ciudadanos de Ecuador (4.82) y Colombia (4.82) son quienes aprueban con mayor vigor esa iniciativa, seguidos en menor medida por México (4.6). Por el contrario, la opinión pública recibe con poco entusiasmo la entrada de tropas estadounidenses en sus territorios para resolver el problema. Esta vez son los ciudadanos ecuatorianos (3.6) y colombianos (3.7) quienes expresan mayor negativa frente a esta idea, mientras que los mexicanos (4) se muestran como los más abiertos. Así, es posible observar una mayor reticencia frente a aquellas acciones que implique ceder soberanía dentro del territorio nacional, lo cual es coherente con la hipótesis del anti-americanismo.

Siguiendo con las percepciones de los latinoamericanos sobre la cooperación con Estados Unidos en materia de seguridad, los cuestionarios de 2008, 2010 y 2012 incluyeron una pregunta específica sobre si se está a favor o en contra de recibir ayuda financiera estadounidense para el combate al narcotráfico y al crimen organizado. En 2008 la pregunta sólo se realizó en Colombia y México, donde 72 y $55 \%$ respectivamente están a favor, 15 y $36 \%$ en contra y 12 y $7 \%$ dudarían dependiendo de la situación. Es interesante resaltar las diferencias entre estos dos países, ya que ambos aparecen como grandes escenarios de la "guerra contra las drogas" en la región y como receptores importantes de ayuda financiera y técnica por parte de Washington.

En 2010 Colombia y México mantuvieron la misma tendencia con 74 y $54 \%$ de los encuestados a favor de recibir ayuda financiera de Estados Unidos para el combate al narcotráfico y al crimen organizado. Los encuestados de Ecuador y Perú mostraron una propensión similar a la aceptación de la ayuda estadounidense con 72 y $63 \%$ respectivamente. Esta posición, sin embargo, se matiza una vez se incluyen condicionamientos para la recepción y la ejecución de tales recursos. Al preguntar a los encuestados de los cuatro países si estarían de acuerdo con recibir esos recursos pero con la supervisión estadounidense de los mismos, se observa una disminución en tal aprobación en los casos de Colombia (pasa de 74 a $67 \%$ ), Ecuador (de 72 a 47\%) y Perú (de 63 a 49\%). En el 
caso de México esta aprobación, en cambio, se incrementa en 4 puntos porcentuales de 54 a $58 \%$.

Esta disminución es todavía mayor para los casos de Colombia, Ecuador y Perú cuando la ayuda financiera se condiciona al envío de agentes estadounidenses para que operen dentro del país. La favorabilidad para esta ayuda en Colombia desciende hasta $36 \%$, mientras que su oposición crece a 47\%; en Ecuador se llega a una favorabilidad de $37 \%$ frente a una oposición de $49 \%$; y en Perú la oposición crece hasta $49 \%$, mientras que la favorabilidad disminuye hasta $35 \%$. México en cambio muestra una tendencia contraria, donde la favorabilidad se mantiene estable (57\%) frente al condicionamiento de la supervisión de los recursos, al tiempo que la oposición disminuye hasta $26 \%$.

Los datos de 2012 obtenidos de las encuestas de Colombia y México muestran que, para el caso del primero, hay una disminución de la favorabilidad de la ayuda financiera estadounidense para el combate al narcotráfico y al crimen organizado, aun sin condiciones. Para el caso del segundo se observa un leve descenso de la favorabilidad a esta ayuda; sin embargo, al incluir los condicionamientos, la favorabilidad mexicana aumenta siempre y cuando haya una supervisión de los recursos por parte de la Casa Blanca, como se puede observar en las gráficas 7a, 7b y 7c.

Podemos decir que la opinión pública latinoamericana es consciente del lugar que ocupa Estados Unidos en la región como socio de cooperación en seguridad y de los recursos que sus países pueden obtener en esta materia. Pese a las variaciones que se presentan alrededor de estas preguntas, es posible sugerir que los sentimientos de anti y pro-americanismo están atravesados por un alto grado de pragmatismo, según el cual la opinión pública latinoamericana reacciona a favor o en contra de la asociación con Estados Unidos y de su intervención dependiendo de los costos y beneficios que tales acciones impliquen. De allí que se haya construido un sentido común a partir del cual se tiende a favorecer el trabajo cercano con este país, pero siempre guardando la distancia suficiente como para no asumir compromisos que no sean del total agrado de sus países, o hacerlo sólo en el caso en que éstos supongan un beneficio todavía mayor. 


\section{GrÁficA 7a}

Ayuda financiera estadounidense para el combate al narcotráfico. Colombia y México 2008, 2010 y 2012

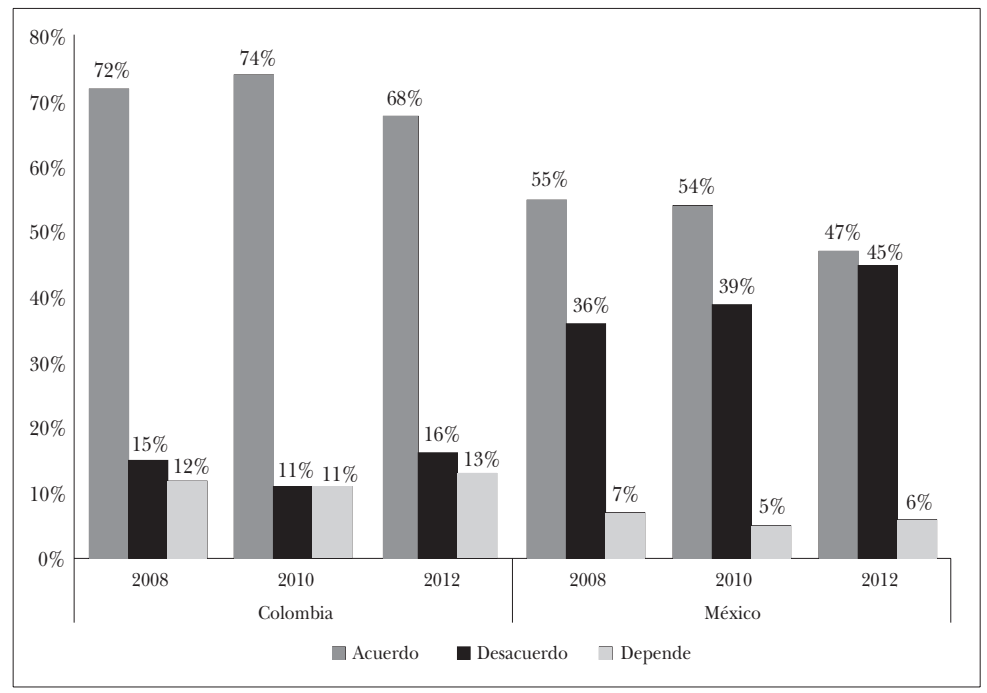

GRÁFICA 7b

Recursos supervisados por Estados Unidos. Colombia y México 2010 y 2012

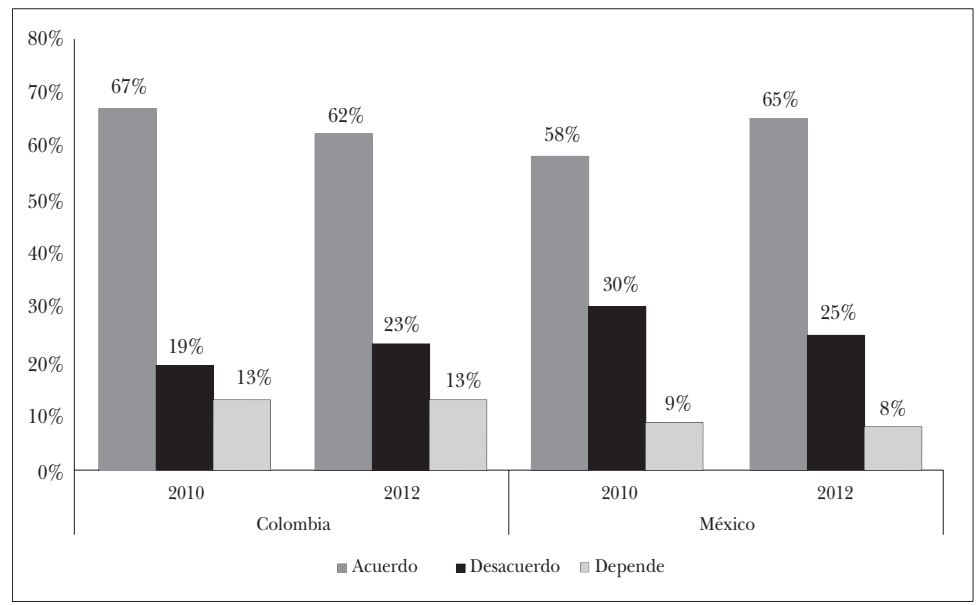


GrÁFICA 7c

Agentes estadounidenses en Colombia y México 2010 y 2012

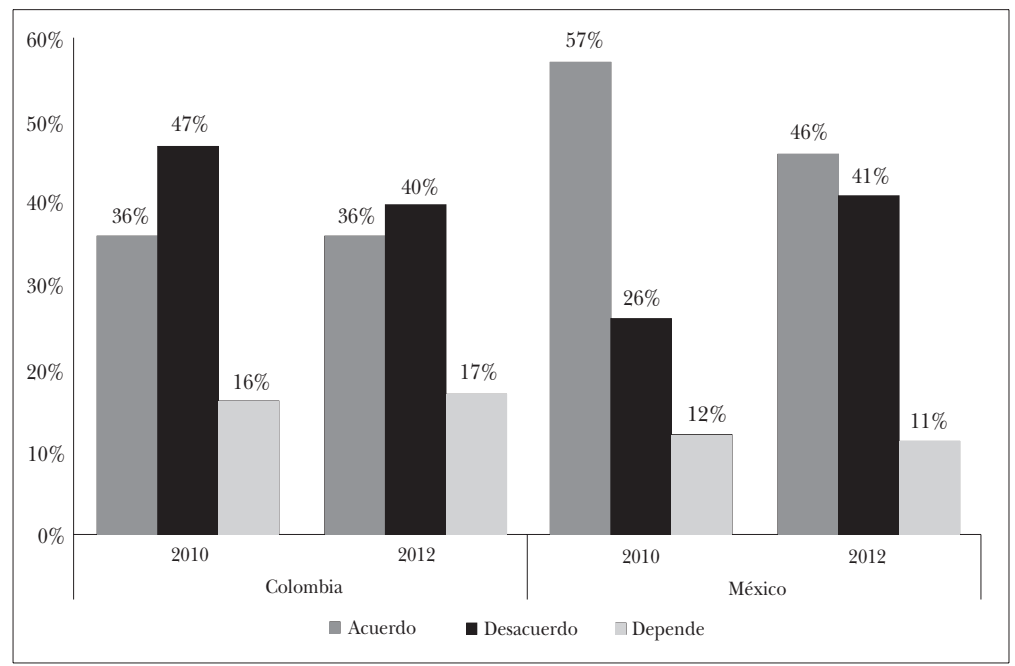

\section{TENDENCIAS ANTI Y PRO-AMERICANAS}

Habiendo dado cuenta de las percepciones centrales de los latinoamericanos frente a la imagen de Estados Unidos y la relación que éste tiene con los países de la región, es posible concluir que no existe un sentido común fácilmente catalogable como pro o anti-americano. Al contrario, encontramos que los latinoamericanos se mueven entre una y otra tendencia dependiendo fundamentalmente de los temas concretos sobre los que se indague y las coyunturas específicas por las que se atraviese.

Pese a ello, se encuentra también que hay una mayor reticencia hacia Estados Unidos en aquellos casos en los que se plantea una mayor intervención por parte de éste y algún tipo de cesión de soberanía por parte de la región. De igual forma, es posible observar una tendencia hacia la valoración positiva de Estados Unidos en términos genéricos, así como de la posible asociación estratégica para los países de la región. 
No es posible hablar de sentimientos de anti o pro-americanismo comunes a todos los países, pero sí es posible identificar tendencias de opinión pública en una u otra dirección que, en la medida en que se mantengan consistentemente en el futuro, podrían dar cuenta de un sentido común afianzado alrededor de temas y problemas específicos.

A continuación se retoman algunas de las tendencias más significativas en la evaluación de lo que Estados Unidos es y lo que hace entre los encuestados de Colombia, Ecuador, México y Perú.

\section{Colombia}

La presencia de un sentido común anti y pro-americanismo varían entre los colombianos en función de cuatro ejes: por un lado, se puede observar que los encuestados tienen una buena percepción de Estados Unidos y de la relación bilateral; por el otro lado, tienen opiniones menos favorables sobre la actuación estadounidense en diversas áreas y una alta reticencia a su intervención en los asuntos de la región.

Fundamentalmente, los colombianos tienen sentimientos de admiración y confianza hacia Estados Unidos, lo que junto con la evaluación que se hace de la relación bilateral en términos positivos, marcan una tendencia hacia el pro-americanismo. Ésta se refuerza con el hecho de que la mayoría de los encuestados describe la relación en clave de sociedad y amistad, al tiempo que privilegia la búsqueda de una asociación estratégica con Estados Unidos antes que la formación de un bloque de Estados Latinoamericanos.

El ejecutivo estadounidense también se evalúa en términos positivos, aunque es importante destacar que el nivel de favorabilidad hacia éste tuvo un incremento importante entre 2008 y 2010, que se explica por el fin de la administración del republicano George W. Bush y la llegada al poder del demócrata Barack Obama. Siguiendo la misma línea, el desempeño estadounidense en áreas como la relación con América Latina, promoción del libre comercio y combate del terrorismo internacional reciben una valoración positiva por parte de los colombianos, lo cual probablemente guarda 
relación con el hecho de que son tres esferas en las cuales el país ha trabajado cerca de Estados Unidos en los últimos veinte años.

Ya en temas como defensa de la democracia y el envío de tropas estadounidenses en situaciones de conflicto, la evaluación de los colombianos se mantiene en términos casi neutrales, asignando valores de 4 y 4.7 en una escala de 1 a 7 respectivamente, por lo que no se muestra una tendencia claramente positiva o negativa hacia Estados Unidos.

Ahora bien, los colombianos ven con buenos ojos el trabajo cercano de su país con Estados Unidos, lo que podría mostrar una tendencia hacia el pro-americanismo, que se materializa, por ejemplo, en la amplia aceptación que tiene la ayuda financiera estadounidense en el combate al narcotráfico; sin embargo, es en esta misma área donde la reticencia hacia Estados Unidos aparece cuando se trata de que haga una supervisión directa de los recursos o los ejecute directamente, con lo que los sentimientos de pro-americanismo desaparecen y son reemplazados por los de un rechazo tajante a la intervención estadounidense. Esto ocurre también en el caso de la hipotética entrada de tropas militares para resolver el problema del narcotráfico, la cual obtiene una evaluación de negativa en términos de eficiencia.

Así, en el caso de Colombia es muy difícil hablar de un sentido común anti o pro-americano completamente afianzado. Es posible identificar algunas tendencias entre la opinión pública, las cuales permiten ver que el alineamiento con Estados Unidos es menor entre la población de lo que puede ser entre las élites y los formuladores de política exterior, sin que ello implique fuertes sentimientos de anti-americanismo. Al contrario, es posible identificar un alto grado de pragmatismo entre los encuestados, que parecen no tener opiniones preconcebidas sobre Estados Unidos, sino percepciones formadas a partir de coyunturas y asuntos concretos, con lo que podría pensarse que lo que prima en el sentido común colombiano no son los sentimientos de anti o pro-americanismo, sino más bien un análisis estratégico sobre lo que se considera más conveniente para el país en situaciones particulares. 


\section{Ecuador}

En un informe reciente del Servicio de Investigación del Congreso de los Estados Unidos sobre la relaciones entre dicho país y Ecuador, ${ }^{37}$ se señala que si bien ambos países han mantenido estrechas relaciones, bajo la administración de Rafael Correa ésta se ha vuelto tensa debido a su estilo de gobierno populista y su postura anti-imperialista. Autores como Julia Sweig, Justice Lance o Sean Goforth ${ }^{38}$ han sido enfáticos en resaltar la presencia de una identidad anti-americana en Ecuador cuyo origen se concentra en la elección de Correa como presidente.

Aunque a simple vista sería imposible negar que la política exterior ecuatoriana ha estado marcada por múltiples posiciones anti-americanas, es erróneo afirmar que Ecuador es un país con una identidad anti-americana, tal y como se observa en su opinión pública de acuerdo con las encuestas de 2010 y 2012, que sustentan la idea de que en Ecuador hay una percepción positiva sobre Estados Unidos que aumenta desde la primera administración de Obama. Los sentimientos de admiración y confianza llegan a niveles similares a los de Colombia o Perú, países tradicionalmente catalogados como pro-americanos.

Los ecuatorianos no sólo tienen una buena imagen de Estados Unidos, sino también de la relación bilateral. Cerca de $80 \%$ considera que la relación es importante y otro $60 \%$ que es buena, lo cual no está lejos de la realidad si se toma en cuenta que Estados Unidos es el principal socio comercial del Ecuador, representando aproximadamente $40 \%$ de las exportaciones. ${ }^{39}$ Incluso en 2010, la opinión pública prefería buscar un trato especial con Washington a fin de satisfacer los intereses, antes que coordinar posiciones con los países latinoamericanos.

${ }^{37}$ June S. Beittel, "Ecuador: Political and Economic Conditions and U.S. Relations”, Congressional Research Service. Disponible en http://fas.org/sgp/crs/row/ R43135.pdf

${ }^{38}$ Sean Goforth, "A Manifestation of Anti-Americanism in the Andes", World Politics Review, 11 de agosto de 2010, p. 2.

${ }^{39}$ June S. Beittel, "Ecuador: Political and...", p. 4. 
$\mathrm{Al}$ observar el comportamiento frente a la política exterior estadounidense, el pro-americanismo reluce con algunas excepciones. El desempeño en áreas como defensa de la democracia, lucha antiterrorista, promoción del libre comercio y cooperación militar, es evaluado de manera positiva. En cuanto a la lucha contra el narcotráfico y el crimen organizado, los ciudadanos ven en la extradición hacia Estados Unidos una herramienta eficaz para enfrentar el problema. En segundo lugar, para responder a esa amenaza, son receptivos a la ayuda financiera, lo cual se contradice con varias de las medidas que ha adoptado el gobierno de Rafael Correa en este tema. ${ }^{40}$

Los puntos donde se puede encontrar un sentido común antiamericano son los mismos que generan rechazo entre de la opinión pública de varios países de América Latina. La opinión pública ecuatoriana rechaza cualquier intervención o participación de tropas estadounidenses en territorio ecuatoriano con el objetivo de enfrentar el problema del narcotráfico. Finalmente, al igual que en México y Colombia, los ecuatorianos desaprueban la política exterior que Estados Unidos ha mantenido hacia Cuba. No sólo es la dimensión que más rechazo provoca entre la opinión pública, sino que también ha sido una de las denuncias de mayor recurrencia en los discursos de Rafael Correa.

\section{México}

México no es un caso fácil de clasificar como un país con identidad anti o pro-americana, sin tener en cuenta los diferentes temas en los cuales Estados Unidos aparece como un actor central y sus respectivos matices. Sin embargo es importante señalar que sí hay una tendencia mucho más marcada hacia la desconfianza frente a lo que Estados Unidos es.

Si bien la mayoría de los mexicanos describe la relación de su país con Estados Unidos en términos de sociedad y de amistad, al tiempo que reconocen que es altamente importante, es necesario

${ }^{40}$ Véase el International Narcotics Control Strategy Report del año 2013. 
destacar que porcentajes significativos en 2008 (61\%), 2010 (45\%) y $2012(40 \%)$ tienen sentimientos de desconfianza hacia este país, lo que puede comprenderse en un marco general de anti-americanismo fundamentado en percepciones históricas de amenazas desde el norte.

Por otro lado, hay un reconocimiento de la importancia de las relaciones con Estados Unidos, lo cual se refleja también en la percepción de que el país debería privilegiar la búsqueda de un trato preferencial por parte de Estados Unidos por encima de la construcción de un bloque regional latinoamericano. Esto no supone necesariamente el arraigo de sentimientos pro-americanos entre los mexicanos, y por consiguiente un sentido común positivo hacia ese país, sino una muestra de reconocimiento y comprensión de la importancia real que tiene Estados Unidos tanto para la política exterior, como para la política interna del país.

El ejecutivo estadounidense, al igual que en los otros casos, recibe una calificación relativamente negativa $(45 / 100)$ durante la administración Bush, pero mejora con la llegada de Obama a la Casa Blanca (63 y 64 en 2010 y 2012 respectivamente). El desempeño de Estados Unidos en áreas como la promoción del libre comercio y el combate al terrorismo global se evalúa positivamente, mientras que temas como la relación con América Latina, la defensa de la democracia y el envío de tropas militares a territorios en situaciones de conflicto reciben una evaluación neutral y el manejo a los asuntos con Cuba se califica negativamente. Así, no es posible establecer una sola tendencia, sino más bien opiniones que varían de acuerdo a contextos y situaciones particulares.

La distancia con Estados Unidos aparece con respecto a qué tan conveniente es trabajar cerca de este país. Si bien la mayoría de los mexicanos lo ve como algo positivo, no lo hacen en la misma proporción que su contraparte colombiana y el rechazo aumenta cuando esa cercanía supone compromisos que el país no quisiera adquirir. Es entonces posible identificar una cierta tendencia anti-americana en esta materia, alimentada por los sentimientos de desconfianza mencionados, que dan cuenta de un sentido común en esa dirección en lo que respecta a la cooperación con Estados Unidos. 
A pesar de ello, esta tendencia se matiza cuando se plantea la posibilidad de obtener recursos de cooperación para el combate al narcotráfico. La mayoría de los encuestados se muestra favorable a su recepción, pero, contrario a lo que ocurre con los demás países latinoamericanos, los niveles de aceptación crecen cuando se plantea un mayor grado de intervención estadounidense, ya sea supervisando los recursos o ejecutándolos directamente. Este dato, además de sorprendente, resulta fundamental para analizar cualquier argumento alrededor de un supuesto sentido común anti-americano homogéneo entre los mexicanos.

Así las cosas, es posible identificar algunas dimensiones del sentido común de las masas que, más allá de dar cuenta de un anti o pro-americanismo, permiten entender la complejidad de la relación bilateral con Estados Unidos, la cual aparece casi que como un eje central de la política mexicana. Ésta, sin embargo, está lejos de ser una relación sencilla; presenta elementos de competencia e interdependencia que han alimentado los sentimientos de desconfianza, por un lado, y el reconocimiento de la necesidad de un trabajo conjunto, por el otro.

\section{Perú}

En Perú, pese a que la opinión de los ciudadanos varía cuando se trata de evaluar entre lo que Estados Unidos es y lo que hace, los resultados revelan que la opinión pública muestra tendencias hacia un sentido común pro-americano que se refleja en los sentimientos de admiración y confianza. No obstante, hay variaciones importantes debido a los cambios del gobierno estadounidense. En 2008 la evaluación negativa de la imagen del ejecutivo en manos de George W. Bush estuvo acompañada de altos niveles de desconfianza que no son comparables a los de ningún otro país de la muestra.

Los peruanos describen la relación bilateral en términos de sociedad, lo que no revela una posición negativa o positiva frente a Estados Unidos, pero sí expresa una relación intersubjetiva que está regulada por normas distintas a las que habría si Estados Unidos se 
considerara un rival, una amenaza o un amigo, lo cual parece no ser algo exclusivo de la opinión pública. Según señala Ronald Bruce St. John, ${ }^{41}$ en la política exterior peruana predomina una posición pragmática frente a Estados Unidos antes que cualquier cosa, especialmente desde el gobierno de Alejandro Toledo (2001-2006) hasta la administración de Alan García (2006-2011).

Por otra parte, los encuestados toman distancia de Estados Unidos en algunos aspectos. Existe un rechazo importante frente a la toma de decisiones de manera conjunta y el envío de agentes que operen en el territorio nacional, donde la soberanía puede aparecer como un elemento central. De igual forma se prefieren los esquemas de cooperación con los países de la región para defender sus intereses sobre la búsqueda de una relación privilegiada con Estados Unidos; sin embargo, al indagar por temas que no cuestionan la soberanía nacional la población es más receptiva, como en el caso de recibir ayuda financiera para combatir problemas como el narcotráfico y el crimen organizado.

Esta tendencia se ha contrapuesto a la política exterior peruana. Desde mediados de los años noventa, ambos países han sido grandes aliados en la promoción del libre comercio y la guerra contra las drogas; han logrado, por un lado, la firma de un TLC y, por el otro, una impresionante disminución de los cultivos de coca en los últimos años. ${ }^{42}$

\section{Conclusiones}

Las percepciones de la opinión pública latinoamericana, tal y como se expresan en la encuesta Las Américas y el Mundo, indican que es necesario matizar las afirmaciones de que en la región

${ }^{41}$ Ronald Bruce St. John, "Ideology and Pragmatism in the Foreign Policy of Peru”, en Gian Luca Gardini y Peter Lambert (eds.), Latin American Foreign Policies, Nueva York, Palgrave Macmillan, 2007, pp. 119-138.

42 Cynthia McClintock y Fabián Vallas, "The United States, and Peru in the 2000s”, en Jorge I. Domínguez y Rafael Fernández de Castro (eds.), Contemporary U.S.-Latin American Relations: Cooperation or Conflict in the 21st Century?, Nueva York, Routledge, 2010, pp. 197-217. 
existe un marcado y singular anti-americanismo. Consideramos problemático atribuir, como hace la mayoría de la literatura existente, una identidad concreta y única a los Estados latinoamericanos, o a la región, como un todo en términos de anti-americanismo, sólo a partir de los discursos de las élites, de las decisiones que toman o de las percepciones que éstas tienen. En contraposición a este lugar común acerca de América Latina, al tomar en cuenta la opinión pública podemos observar que tanto el pro como el anti-americanismo se expresan alrededor de temas y coyunturas específicos.

Nuestro análisis sugiere que entre los latinoamericanos se ha construido un sentido común dentro del cual existe una imagen favorable de la asociación estratégica con Estados Unidos, fruto de la importancia y las ganancias que se pueden obtener de una relación cercana con la potencia, al tiempo que se reconoce la necesidad de desarrollar lazos con los demás países del hemisferio y de mantener ciertos niveles de autonomía. Sin embargo, es posible encontrar contextos nacionales en donde la favorabilidad hacia Estados Unidos es mayor que en el resto de la región, como es el caso de Colombia, o donde se tiende a valorar en términos positivos la supervisión estadounidense en la asignación y ejecución de recursos financieros de cooperación, como en el caso de México.

De igual forma, podemos resaltar elementos que dan cuenta de la coexistencia de elementos de pro y anti-americanismos en el sentido común latinoamericano, como por ejemplo los altos niveles de admiración hacia Estados Unidos acompañados por niveles, al menos significativos, de desconfianza hacia este país. Esa paradoja se materializa en opiniones sobre la cooperación estadounidense en la región, la cual es ampliamente aceptada y sugiere la existencia de sentimientos pro-americanos, y la resistencia a la intervención estadounidense, lo cual es coherente con la desconfianza y los posibles sentimientos anti-americanos.

Adicionalmente, se esperaría que el anti-americanismo se manifestara por efecto de actitudes concretas hacia Estados Unidos, como por ejemplo la definición de la relación en términos de amistad, sociedad, rivalidad o amenaza. Porcentajes inferiores a $10 \%$ califican la relación en términos de amenaza y menos del $5 \%$ considera que ésta es mala o muy mala. Esto contrasta con las actitudes 
de Paquistán, Egipto, Turquía y Jordania, donde 80, 79, 72 y $86 \%$ respectivamente tienen una opinión desfavorable de Estados Unidos, según datos del proyecto sobre actitudes globales del Pew Research Center de 2012, ${ }^{43}$ siendo el primero el caso más dramático con $74 \%$ de su población percibiendo a Estados Unidos como un enemigo.

\section{Bibliografía}

Applebaum, Anne, "In Search of Proamericanism", Foreign Policy, 1 de julio de 2005, pp. 32-40.

Ayerbe, Luis Fernando, "Antiamericanismo en América Latina: Percepciones y realidades", Anuario de Integración Latinoamericana y del Caribe, vol. 1, 2007, pp. 100-105.

Bell, Philip y Roger Bell, "Americanization: Political and Cultural Examples from the Perspective of 'Americanized' Australia”, American Studies, vol. 37, núm. 1, 1996, pp. 1-21.

Baker, Andy y David Cupery, "Anti-Americanism in Latin America. Economic Exchange, Foreign Policy Legacies, and Mass Attitudes toward the Colossus of the North", Latin American Research Review, vol. 48, núm. 2, 2013, pp. 106-130.

Beittel, June S., "Ecuador: Political and Economic Conditions and U.S. Relations", Congressional Research Service. Disponible en http://fas. org/sgp/crs/row/R43135.pdf

Cancino, Arturo y Carolina Albornoz, "La integración regional como instrumento de desarrollo para América Latina”, Colombia Internacional, núm. 66, 2007, pp. 120-146.

Chabat, Jorge, "La Iniciativa Mérida y la relación México-EEUU: en busca de la confianza perdida", Documento de trabajo del CIDE, núm. 195, 2010, pp. 1-13.

Checkel, Jeff, "Ideas, Institutions, and the Gorbachev Foreign Policy Revolution”, World Politics, vol. 45, núm. 2, 1993, pp. 271-300.

Crandall, Rusell, "The Post-American Hemisphere: Power and Politics in

${ }^{43}$ Pew Research Center (2012), Pakistani Public Opinion. Ever More Critical of U.S. Disponible en: http://www.pewglobal.org/files/2012/06/Pew-Global-Attitu des-Project-Pakistan-Report-FINAL-Wednesday-June-27-2012.pdf. 
an Autonomous Latin America”, Foreign Affairs, vol. 9, núm. 3, 2011, pp. 83-90.

Croci, Osvaldo, "The 'Americanization' of Italian Foreign Policy?”, Journal of Modern Italian Studies, vol. 10, núm 1, 2007, pp. 10-26.

Dugas, John C., "Colombian Attitudes toward the United States after 9/11", en Vladimir Shlapentokh, Joshua Woods y Eric Shiraev (eds.), America: Sovereign Defender Or Cowboy Nation?, Burlington, Ashgate, 2005, pp. 71-88.

Finnemore, Martha y Kathryn Sikkink, "International Norm Dynamics and Political Change”, International Organization, vol. 52, núm. 4, 1998, pp. 887-917.

Goforth, Sean, "A Manifestation of Anti-Americanism in the Andes", World Politics Review, 11 de agosto de 2010, p. 2.

Grandin, Greg, “The Narcissism of Violent Differences”, en Andrew Ross y Kristin Ross (eds.), Anti-americanism, Nueva York, New York University Press, 2004, pp. 17-31.

, "Your Americanism and Mine: Americanism and Anti-Americanism in the Americas", The American Historical Review, vol. 111, núm. 4, 2006, pp. 1042-1066.

Holsit, Ole R., "Public Opinion and Foreign Policy: Challenges to the Almond-Lippmann Consensus”, International Studies Quarterly, vol. 36, núm. 4, 1992, pp. 439-466.

Hopf, Ted, "Common-sense Constructivism and Hegemony in World Politics”, International Organization, vol. 67, núm. 2, 2013, pp. 317-354.

- , "The Promise of Constructivism in International Relations Theory", International Security, vol. 23, núm. 1, 1998, pp. 171-200.

Jentleson, Bruce W., "The Pretty Prudent Public: Post Post-Vietnam American Opinion on the Use of Military Force", International Studies Quarterly, vol. 36, núm. 1, 1992, pp. 49-73.

Katzenstein, Peter J. y Robert O. Keohane, "Varieties of Anti-Americanism: A Framework for Analysis", en Peter J. Katzenstein y Robert O. Keohane (eds.), Anti-Americanisms in World Politics, Ithaca, Cornell University Press, 2007, pp. 9-38.

Keohane, Robert O. y Peter J. Katzenstein, "Introduction: The Politics of Anti-Americanisms", en Peter J. Katzenstein y Robert O. Keohane (eds.), Anti-Americanisms in World Politics, Ithaca, Cornell University Press, 2007, pp. 1-9. 
Knopf, Jeffrey W., "How Rational is the Rational Public? Evidence from U.S. Public Opinion on Military Spending”, The Journal of Conflict Resolution, vol. 42, núm. 5, 1996, pp. 544-571.

Lance, Justice, "Populism and Anti-Americanism in Modern Latin America", Origins: Current Events in Historical Perspective, vol. 1, núm. 1, 2007.

McClintock, Cynthia y Fabian Vallas, "The United States, and Peru in the 2000s”, en Jorge I. Domínguez y Rafael Fernández de Castro (eds.), Contemporary U.S.-Latin American Relations: Cooperation or Conflict in the 21st Century?, Nueva York, Routledge, 2010, pp. 197-217.

McPherson, Alan, "Anti-Americanism in Latin America", en Brendon O'Connor (ed.), Anti-americanism: History, Causes, Themes, vol. 3: Comparative Perspectives, Oxford, Greenwood World Publishing, 2007, pp. 77-101.

_, "Anti-americanism in Latin America and the Caribbean. False Populismo or Coming Full Circle", en Ivan Krastev y Alan McPherson (eds.), The Anti-American Century, Budapest, European University Press, 2007, pp. 49-75.

, Yankee No! Anti-Americanism in U.S.-Latin American Relations, Cambridge, Harvard University Press, 2003.

Mejía, Daniel y Pascual Restrepo, "The War on Illegal Drug Production and Trafficking: An Economic Evaluation of Plan Colombia”, Documento de Trabajo CEDE, núm. 19, 2008, pp. 1-60.

Moehler, Devra y van de Nicolas Walle, "Pro- and Anti-Americanism in Sub-Saharan Africa", Paper presented at the annual meeting of the International Communication Association, Suntec Singapore International Convention \& Exhibition Centre, Suntec City, Singapur, 21 de junio de 2010. Disponible en: http://citation.allacademic.com/ meta/p_mla_apa_research_citation/4/0/3/7/3/p403735_index.html

Park, Seong Wong, "The Present and Future of Americanization in South Korea”, Journal of Futures Studies, vol. 14, núm. 1, 2009, pp. 51-66.

Pratt, Mary Louise, "Back Yard with Views", en Andrew Ross y Kristin Ross (eds.), Anti-americanism, Nueva York, New York University Press, 2004, pp. 32-45.

Radu, Michael, "A Matter of Identity: The Anti-Americanism of Latin American Intellectuals", en Paul Hollander (ed.), Understanding Anti-Americanism: Its Origins and Impact at Home and Abroad, Chicago, Ivan R. Dee, 2004, pp. 144-164. 
Rosati, Jerel A. y James C. Scott, The Politics of the United States Foreign Policy, Boston, Wadsworth, 2011.

Rupert, Mark, "Gramsci”, en Jeny Edkins y Nick Vaughan-Williams (eds.), Critical Theorists and International Relations, Nueva York, Routledge, 2009, pp. 166-186.

St. John, Ronald Bruce, "Ideology and Pragmatism in the Foreign Policy of Peru”, en Gian Luca Gardini y Peter Lambert (eds.), Latin American Foreign Policies, Nueva York, Palgrave Macmillan, 2007, pp. 119-138.

Sweig, Julia E., Friendly Fire, Nueva York, Public Affairs, 2006.

Walker, William O., III, "The United States, Colombia, and Drug Policy, 1984-2004. A Study Of Quiet Anti-Americanism”, en Alan McPherson (ed.), Anti-Americanism in Latin America and the Caribbean, Nueva York, Berghahn Books, 2006, pp. 239-270.

Wendt, Alexander, "Collective Identity Formation and the International State”, The American Political Science Review, vol. 88, núm 2, 1994, pp. 384-396.

Weldes, Jutta, "Constructing National Interests", European Journal of International Relations, vol. 2, núm. 3, 1996, pp. 275-318.

Yoshiyuki, Tsurumi, "Americanism in Postwar Japan: Political Consciousness on Pro/Anti-American Sentiment", AJForum10, 2007. Disponible en: http://www.a-jrc.jp/pdf/ajforum/ajforum10summary_en.pdf

Yudice, George, "U.S. Prepotencia. Latin Americans Respond”, en Andrew Ross y Kristin Ross (eds.), Anti-americanism, Nueva York, New York University Press, 2004, pp. 69-85. 